\title{
Carbon Dots Derived from the Maillard Reaction for pH Sensors and Cr (VI) Detection
}

\author{
Zhi Ma ${ }^{1}$, Yun Ma ${ }^{1}$, Meiyu Gu ${ }^{1}$, Xiyue Huo ${ }^{1}$, Sainan Ma ${ }^{1}$, Yini Lu ${ }^{1}$, Yao Ning ${ }^{1}$, Xuan Zhang ${ }^{1}$, \\ Bo Tian ${ }^{1, *}$ and Zhibiao Feng ${ }^{2, *}$ \\ 1 College of Food Science, Northeast Agricultural University, Harbin 150030, China; \\ mxrex215@163.com (Z.M.); mayunneau@163.com (Y.M.); gumeiyu0913@163.com (M.G.); \\ neauhuoxiyue@126.com (X.H.); neaumasainan@126.com (S.M.); lyn7310@163.com (Y.L.); \\ nya163@163.com (Y.N.); zhang862129527@126.com (X.Z.) \\ 2 Department of Chemistry, Northeast Agricultural University, Harbin 150030, China \\ * Correspondence: tianbo@neau.edu.cn (B.T.); fengzhibiao@neau.edu.cn (Z.F.); Tel.: +86-451-5519-04-79 (B.T.); \\ $+86-451-5519-02-22$ (Z.F.)
}

Received: 24 August 2020; Accepted: 24 September 2020; Published: 26 September 2020

check for updates

\begin{abstract}
The Maillard reaction involves a series of complex reactions; fluorescent compounds have been considered as vital intermediate products of the reaction. In this article, carbon dots (CDs) based on the Maillard reaction (MR-CDs) were prepared with L-tryptophan and D-glucose, and they had excellent photoluminescence stability. MR-CDs showed stable $\mathrm{pH}$-dependence behavior and exhibited an excellent linear response to $\mathrm{pH}$ in the range of 4.0-7.5 and 7.5-13.0, respectively. Under the masking effect of sodium fluoride for Fe(III), MR-CDs showed excellent selectivity and sensitivity for $\mathrm{Cr}(\mathrm{VI})$. The linear range of $\mathrm{Cr}(\mathrm{VI})$ was $0.2-50 \mu \mathrm{M}$ and the limit of detection was $20 \mathrm{nM}$. $(\mathrm{S} / \mathrm{N} \geq 3)$. Furthermore, MR-CDs were used to detect $\mathrm{Cr}(\mathrm{VI})$ in tap water samples. The recoveries were between $95.8 \%$ and $98.94 \%$, and RSDs were less than $3.17 \%$.
\end{abstract}

Keywords: Maillard reaction; carbon dots; L-tryptophan; D-glucose; $\mathrm{pH}$ dependence; $\mathrm{Cr}(\mathrm{VI})$ detection

\section{Introduction}

Carbon dots (CDs) are a class of carbon nanoparticles with particle sizes ranging from 1 to $10 \mathrm{~nm}$. Due to their unique fluorescence properties, such as anti-photobleaching and high photoluminescence characteristics, they have been widely used as fluorescent probes [1-3]. Over the past years, different synthetic methods have been developed to prepare CDs. Generally, these methods are classified into hydrothermal synthesis, solvothermal synthesis, chemical oxidation and microwave/ultrasonic synthesis, etc. [4]. Although various materials have been used to prepare CDs, the synthesis strategy is still limited to screening small molecule organics for doping and little attention has been paid to endogenous fluorescence products from the Maillard reaction [5].

The Maillard reaction also called nonenzymatic browning, was first described by Louis-Camille Maillard in 1912 [6]. It is a series of parallel and continuous chemical reactions between the carbonyl-groups of reducing carbohydrates and the amino groups of amino compounds. It frequently occurs in the process of processing, cooking and storage of foods, in which a variety of reaction products are formed, including fluorescent compounds [7]. Fluorescence is characteristically produced during the intermediate stages of the Maillard reaction [8-10]. Recently, several reports showed that CDs could be prepared from the Maillard reaction, such as the pyrolysis process of chicken eggs, milk and orange juice [11-13]. Therefore, CDs can be prepared through controlling the process of the Maillard reaction. This reaction may provide a general method for the preparation of CDs.

In the past decade, emerging studies have shown that CDs used as fluorescence probes have drawn significant attention in the fields of metal ions detection and $\mathrm{pH}$ sensing due to their excellent optical 
properties. Chromium is a typical heavy metal pollutant in drinking water that is released through many industrial operations such as metallurgy, electroplating, pigments and leather tanning [14,15]. It exists in various oxidation states ranging from $\mathrm{Cr}(\mathrm{II})$ to $\mathrm{Cr}(\mathrm{VI})$. Among them, $\mathrm{Cr}(\mathrm{VI})$ is regarded as the most toxic, mutagenic and carcinogenic chemical state [16]. The permissible total chromium in drinking water recommended by the WHO is $50 \mu \mathrm{g} / \mathrm{L}$ (about $1 \mu \mathrm{M}$ ) [17]. Analytical methods such as atomic absorption spectroscopy, high-performance liquid chromatography and UV-visible spectroscopy, have been widely used to detect $\mathrm{Cr}(\mathrm{VI})$. Although these methods are sufficiently sensitive and selective, the complex pre-processing procedures, expensive equipment and time-consuming operation are still limitations to their applications. Fluorescence analysis has assumed an increasingly active role in quantitative analysis of trace metal ions due to its rapid response, high sensitivity and selectivity. For instance, Wang et al. synthesized nitrogen-doped CDs via hydrothermal treatment method to detect $\mathrm{Cr}(\mathrm{VI})$. The nitrogen-doped CDs can be selectively quenched by $\mathrm{Cr}(\mathrm{VI})$, and the detection limit was calculated as $4.16 \mu \mathrm{M}$ [18]. Another related research was carried out by Zhang et al. [19]. The nitrogen and sulfur co-doped CDs were obtained by the pyrolysis process with citric acid and thiourea. A fluorescence assay was proposed for detection of $\mathrm{Cr}(\mathrm{VI})$ via the quenching of MR-CDs, and the limit of detection was $0.2 \mu \mathrm{M}$. Although various CDs were prepared to detect $\mathrm{Cr}(\mathrm{VI})$, it is still important to develop more sensitive CDs for determination of $\mathrm{Cr}(\mathrm{VI})$.

$\mathrm{pH}$ is a crucial target parameter in the industrial, biomedical and environmental applications [20]. Traditional small molecule $\mathrm{pH}$ probes usually suffer from relatively narrow and weak absorption spectra, toxicity concerns, poor emission performance and low photobleaching resistance [21]. The CDs as novel fluorescent nanomaterial has unique properties, especially low toxicity and biocompatibility. Furthermore, CDs are very sensitive to $\mathrm{pH}$ due to the abundant surface functional groups [22]. To date, quantities of CDs with neutral [23], acidic [24,25] or alkaline sensitivity [26] have been generally exploited to measure the $\mathrm{pH}$ of environmental or biologic samples. Nevertheless, most CDs suffer from the general problem of functioning over a small $\mathrm{pH}$ range so as to limit their applications. Therefore, it is essential to develop CDs as fluorescent $\mathrm{pH}$ probes to detect $\mathrm{pH}$ value with a wide range.

In this work, MR-CDs were prepared from the Maillard reaction model system of sugars and L-tryptophan. The factors, including type of sugars, molar ratio of L-tryptophan to D-glucose and $\mathrm{pH}$ value, were investigated. The particle size, optical characteristics, surface groups and elemental composition of MR-CDs were characterized, respectively. MR-CDs showed great $\mathrm{pH}$-sensitive and reversible fluorescence in a wide $\mathrm{pH}$ range, which indicated that MR-CDs could be used as fluorescent $\mathrm{pH}$ probe for environmental samples and living cells. Moreover, we found that MR-CDs were highly selective to $\mathrm{Cr}(\mathrm{VI})$ and $\mathrm{Fe}(\mathrm{III})$. In the presence of sodium fluoride, the quenching effect of Fe(III) was masked, which allowed MR-CDs to be used as a sensitive fluorescent probe for the detection of $\mathrm{Cr}(\mathrm{VI})$ in aqueous media. This method was further used for detecting $\mathrm{Cr}(\mathrm{VI})$ in tap water samples.

\section{Materials and Methods}

\subsection{Materials}

L-tryptophan was obtained from Fine Chemical Research Institute (Tianjin, China). D-glucose and

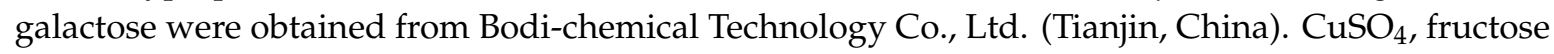
and sucrose were purchased from Kermel Technology Co., Ltd. (Tianjin, China). $\mathrm{K}_{2} \mathrm{Cr}_{2} \mathrm{O}_{7}, \mathrm{CrCl}_{3}$, $\mathrm{HgCl}_{2}, \mathrm{FeCl}_{3}, \mathrm{AlCl}_{3}, \mathrm{PbSO}_{4}, \mathrm{NaCl}$ and $\mathrm{KCl}$ were bought from Benchmark Chemical Reagent Co., Ltd. (Tianjin, China). $\mathrm{MgCl}_{2}$ and $\mathrm{BaCl}_{2}$ were procured from Tianda Chemical Co., Ltd. (Tianjin, China). Ultrapure water was prepared through a Millipore Milli-Q gradient water purification system. All reagents were of analytical grade and were used directly without further purification.

\subsection{Preparation of $M R-C D s$}

L-tryptophan $(0.1022 \mathrm{~g}, 0.5 \mathrm{mmol})$ and D-glucose $(0.2702 \mathrm{~g}, 1.5 \mathrm{mmol})$ were dissolved in $30 \mathrm{~mL}$ ultrapure water. The $\mathrm{pH}$ value of the solution was tuned to 1.0 with $\mathrm{HCl}$ solution (37\%) and then 
transferred the solution into a Teflon reactor. The reactor was heated from room temperature to $200{ }^{\circ} \mathrm{C}$ and held for $6 \mathrm{~h}$. After cooling down to room temperature naturally, the product was centrifuged at $11,040 \times \mathrm{g}$ for $30 \mathrm{~min}$ and the supernatant filtered with a microfiltration membrane. Then, the filtrate was dialyzed against ultrapure water using a dialysis bag (molecular weight cutoff, MWCO 3 kDa) for $48 \mathrm{~h}$. MR-CDs powder was obtained via freeze-drying. Finally, dissolved $5 \mathrm{mg}$ MR-CDs powder in $10 \mathrm{~mL} \mathrm{HCl}-\mathrm{KCl}$ solution $(0.2 \mathrm{M}, \mathrm{pH} 2.5)$ to prepare MR-CDs solution $(0.5 \mathrm{mg} / \mathrm{mL})$ and stored at $4{ }^{\circ} \mathrm{C}$ for further use.

\subsection{Characterization of $M R-C D s$}

The surface morphologies of MR-CDs were characterized by a EM-2100F transmission electron microscope (JEOL Ltd., Tokyo, Japan). Absorption spectra were recorded on a UV-1660 UV-vis spectrophotometer (Shimadzu Corporation, Kyoto, Japan). Fluorescence excitation and emission spectra and intensity were recorded on a RF-6000 fluorescence spectrometer (Shimadzu Corporation, Kyoto, Japan). The Fourier-transform infrared (FTIR) spectra of MR-CDs were recorded on a Tensor-27 Fourier-transform infrared spectrometer (Bruker Corporation, Ettlingen, Germany). X-ray photoelectron spectroscopy (XPS) spectra were used to characterize the chemical composition using a K-Alpha X-ray photoelectron spectrometer (Thermo Fisher Scientific Inc., Waltham, MA, USA).

\subsection{Quantum Yield Measurement of MR-CDs}

The quantum yield $(Q Y)$ of MR-CDs was determined using L-tyrosine as a reference (dissolved in water, $Q Y=14 \%$, excited at $300 \mathrm{~nm}$ ) [20]. Equation (1) was used to determine the quantum yield:

$$
Q Y_{\mathrm{S}}=Q Y_{\mathrm{R}} \times \frac{F_{\mathrm{S}}}{F_{\mathrm{R}}} \times \frac{A_{\mathrm{R}}}{A_{\mathrm{S}}}
$$

where $S$ and $R$ represent the substance and the reference (L-tyrosine), $F$ represents the integrated fluorescence area and A represents the absorption value measured at $300 \mathrm{~nm}$.

\section{5. $p H$ Response of $M R-C D s$}

The solutions with different $\mathrm{pH}$ values were prepared with $\mathrm{HCl}-\mathrm{KCl}$, citric acid- $\mathrm{Na}_{2} \mathrm{HPO}_{4}$, $\mathrm{Na}_{2} \mathrm{~B}_{4} \mathrm{O}_{7}$ and $\mathrm{NaHCO}_{3}-\mathrm{NaOH}$, then $100 \mu \mathrm{L}$ stock solution of MR-CDs was added into $10 \mathrm{~mL}$ solutions of different $\mathrm{pH}$ value ( $\mathrm{pH}$ 1.0-13.0). Then, 10 min later, their fluorescence emission spectra were recorded under $300 \mathrm{~nm}$ excitation.

\subsection{Detection of $\mathrm{Cr}(\mathrm{VI})$}

$\mathrm{Cr}(\mathrm{VI})$ solutions of different concentrations were prepared with $\mathrm{HCl}-\mathrm{KCl}$ solution $(0.2 \mathrm{M}, \mathrm{pH} 2.5)$. Then $100 \mu \mathrm{L}$ MR-CDs stock solution was added to the $\mathrm{Cr}(\mathrm{VI})$ solutions. After $10 \mathrm{~min}$, their fluorescent emission spectra were measured at the excitation wavelength of $300 \mathrm{~nm}$. All analyses were conducted in triplicate.

The calibration curve was obtained by the Stern-Volmer formula:

$$
\frac{F_{0}}{F}=K_{\mathrm{sv}}[\mathrm{Cr}(\mathrm{VI})]+1
$$

where $K_{\mathrm{SV}}$ is the quenching constant, $F_{0}$ and $F$ represent the fluorescence intensity of MR-CDs absence and presence of $\mathrm{Cr}(\mathrm{VI})$.

\subsection{Samples Pretreatment}

Tap water was obtained from the laboratory of Northeast Agricultural University (China). In brief, $1 \mathrm{~mL}$ sodium fluoride $(1 \mathrm{mM})$ was added into $9 \mathrm{~mL}$ tap water and mixed well by magnetic stirring. 
Then, the solution was centrifuged at $11,040 \times g$ for $10 \mathrm{~min}$ and the supernatant was filtered with a $0.45 \mu \mathrm{m}$ membrane.

\section{Results}

\subsection{Preparation of $M R-C D s$}

The fluorescence intensities of MR-CDs were influenced by the type of sugars (D-fructose, sucrose, D-galactose and D-glucose), molar ratio of L-tryptophan to sugars and $\mathrm{pH}$ of reaction environment. As shown in Figure 1a, higher fluorescence intensity was observed in the L-tryptophan-D-glucose Maillard reaction system than in other L-tryptophan-sugars reaction system. Figure 1 b showed the effect of molar ratio of L-tryptophan to D-glucose on the fluorescence intensity of MR-CDs. The addition of D-glucose increased the fluorescence intensity until the molar ratio of L-tryptophan to D-glucose reached 1:3, however, more addition of D-glucose showed an opposite effect on the fluorescence intensity. Furthermore, the emission maxima of MR-CDs red-shifted from 350 to $450 \mathrm{~nm}$ when sugars were incorporated into L-tryptophan. In general, the emission maximum of MR-CDs is related to the energy spacing between the ground state and excited state vibrational energy levels, and the energy spacing is dependent upon the chemical structure of fluorophore [27]. The excitation spectra of MR-CDs are shown in Figure 1c. MR-CDs with and without D-glucose incorporated emitted at $450 \mathrm{~nm}$ and $350 \mathrm{~nm}$, respectively. They had different absorption bands of $\pi-\pi^{*}$ transition at $245 \mathrm{~nm}$. For MR-CDs introduced D-glucose, the absorption band at $245 \mathrm{~nm}$ showed relatively high absorbance and red-shift, which indicated that the introduced of D-glucose extended the conjugated $\pi$ - electron system of MR-CDs. The conjugated $\pi$ electron system intensely coupled with surface electronic states and further reduced the energy gap for the $\pi-\pi^{*}$ transitions. The lower energy gap enhanced the fluorescence intensity and induced a red-shift [3].
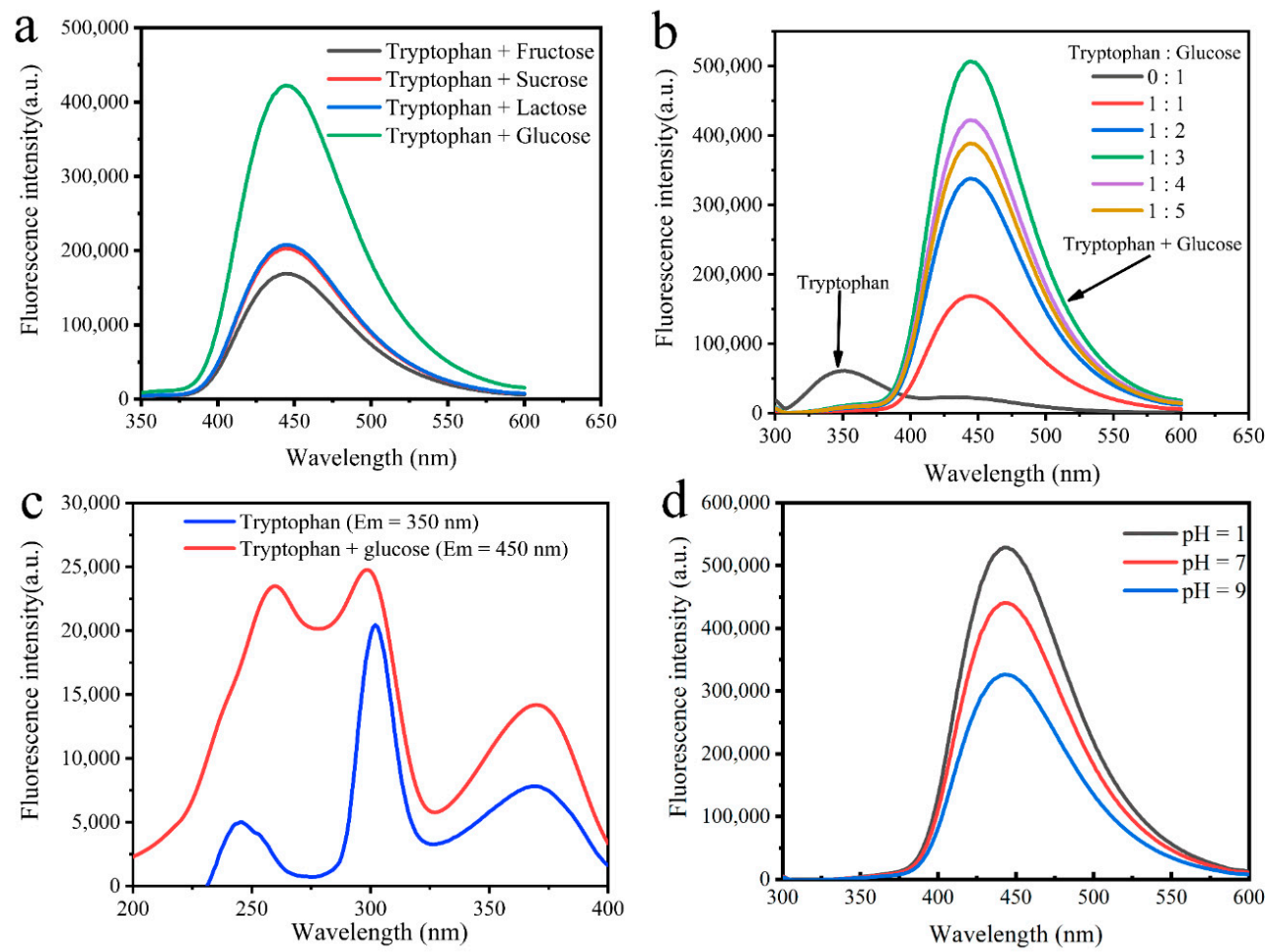

Figure 1. (a) Fluorescence emission spectra of carbon dots (CDs) based on the Maillard reaction (MR-CDs) prepared with L-tryptophan and different sugars; (b) fluorescence emission spectra of MR-CDs prepared from L-tryptophan and D-glucose with various molar ratios; (c) fluorescence excitation spectra of MR-CDs with or without D-glucose (emission wavelength was $450 \mathrm{~nm}$ and $350 \mathrm{~nm}$ ); (d) fluorescence emission spectra of MR-CDs prepared at various $\mathrm{pH}$ values. 
Figure 1d shows the fluorescence emission spectra of MR-CDs prepared in various $\mathrm{pH}$ environments. The fluorescence intensity of MR-CDs decreased while the $\mathrm{pH}$ changed from 9.0 to 1.0, which indicated that the form of MR-CDs strongly depended on the $\mathrm{pH}$ value. In general, the fluorescent compounds formed in the Maillard reaction can be regarded as intermediates during the formation of melanoidins and are also considered as the indicators to detect the early stage of the Maillard reaction [9,28,29]. As shown in the general scheme of the Maillard reaction [30] (Figure S1), the initial Maillard reaction comprises the carbonyl-amino condensation and the formation of Amadori products [31,32]. The process of Amadori rearrangement involves protonation of the nitrogen atoms of glucosyl-amine, and therefore, low pH may induce the formation of fluorescence products [33]. The advanced and final Maillard reaction involves two processes, one is the degradation of Amadori products into sugar-amino compounds, the other is the condensation between amino compounds and sugar fragments into brown pigments (melanoidins) [34]. The brown pigments and fluorescence products are two main components of the advanced Maillard reaction. In this stage, the initial products of condensation are fluorescent, and continuation of the reaction leads to the formation of melanoidins [31,33]. In this work, the lower the $\mathrm{pH}$ was, the more protonated amino groups were present in the Maillard reaction system, and thus, the amino groups were less reactive with sugars. As a result, the low $\mathrm{pH}$ inhibited the formation of melanoidins, and the fluorescent products were also accumulated $[34,35]$.

\subsection{Characterization of $M R-C D s$}

As shown in Figure 2a, MR-CDs displayed a near sphere structure and the average diameter was about 4-5 $\mathrm{nm}$.
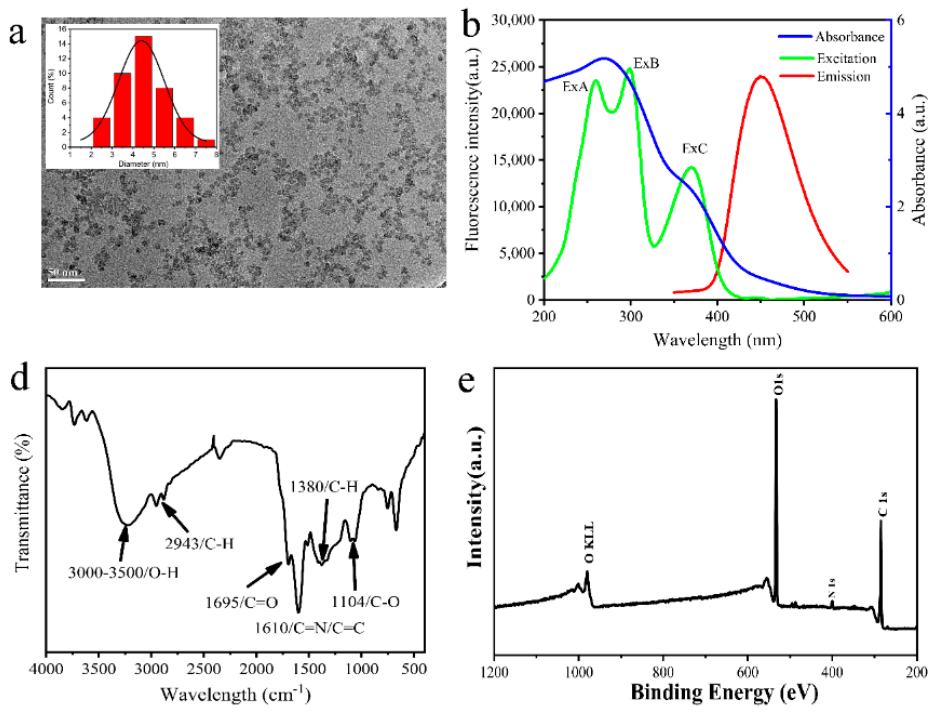
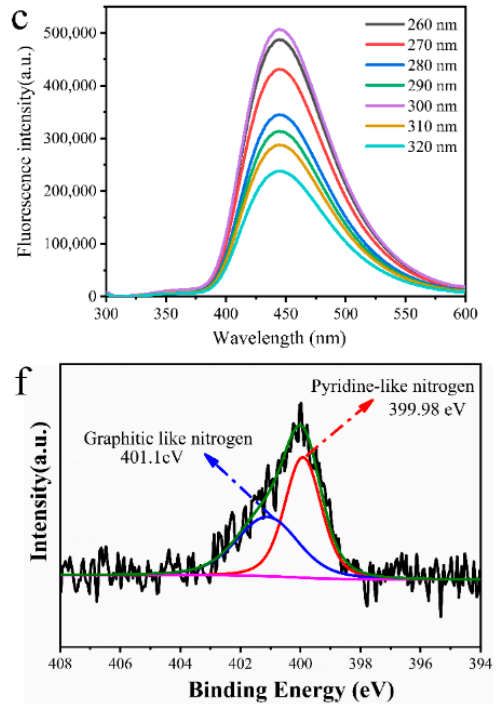

Figure 2. (a) TEM image (inset: particle size distribution); (b) UV-vis absorption spectrum, fluorescence excitation spectrum $\left(\lambda_{\mathrm{em}}=450 \mathrm{~nm}\right)$ and emission spectrum $\left(\lambda_{\mathrm{ex}}=300 \mathrm{~nm}\right)$; (c) fluorescence emission spectra at different excitation wavelengths; (d) FTIR spectrum; (e) XPS spectrum; (f) high-resolution XPS spectrum of N1s.

The optical properties of MR-CDs were explored through UV-vis absorption and fluorescence excitation and emission spectroscopy. As shown in Figure 2b, the UV-vis absorption spectrum showed two absorption bands at $270 \mathrm{~nm}$ and $350 \mathrm{~nm}$, resulting from the $\pi-\pi^{*}$ electronic transition of $\mathrm{C}=\mathrm{C}$ and the $n-\pi^{*}$ transition of surface groups $(C=O$ and $C=N$, etc.), respectively [36,37]. The fluorescence emission spectrum showed three absorption peaks at $258 \mathrm{~nm}(\mathrm{Ex} \mathrm{A}), 300 \mathrm{~nm}$ (Ex B) and $370 \mathrm{~nm}(\mathrm{Ex} \mathrm{C})$, which were consistent with the results of the UV-visible absorption spectrum. The MR-CDs obtained the largest Stokes shift of $150 \mathrm{~nm}$ at excitation wavelength of $300 \mathrm{~nm}$, which minimized the self-absorption 
and reduced the excitation interference. As shown in Figure 2c, the peak position of fluorescence emission spectrum of MR-CDs remained almost unchanged when the excitation wavelength changed from 260 to $320 \mathrm{~nm}$, which suggested that the MR-CDs showed excitation wavelength-independent photoluminescence behavior. This behavior was also reflected in the three-dimensional spectrum (Figure S2), which exhibited three emission peaks, one characteristic peak at $450 \mathrm{~nm}$ and two weak scattering peaks over $300-400 \mathrm{~nm}$. In addition, the QY of MR-CDs was calculated to be $18 \%$, which was comparable to those of most amino acid-derived CDs reported previously [38-40].

The surface functional groups of MR-CDs were investigated using Fourier-transform infrared spectroscopy measurement. As can be seen in Figure 2d, the broad absorption peak from $3000-3500 \mathrm{~cm}^{-1}$ was ascribed to $\mathrm{O}-\mathrm{H}$ stretching vibration, which indicated there were many associative hydroxyl groups existing on the surface of MR-CDs [37]. The sharp peak at $1610 \mathrm{~cm}^{-1}$ was attributed to the stretching vibration of $\mathrm{C}=\mathrm{C} / \mathrm{C}=\mathrm{N}$ bonds [41]. The medium intensity absorption peaks centered at $1380 \mathrm{~cm}^{-1}$ and $2943 \mathrm{~cm}^{-1}$ were ascribed to the $\mathrm{C}-\mathrm{H}$ bending vibration. The absorption peaks at $1104 \mathrm{~cm}^{-1}$ and $1695 \mathrm{~cm}^{-1}$ were ascribed to the $\mathrm{C}-\mathrm{O}$ and $\mathrm{C}=\mathrm{O}$ stretching vibration, respectively [42].

The elements and functional groups information of MR-CDs were further confirmed by XPS analysis. As exhibited in Figure 2e, the full XPS spectrum of MR-CDs showed three typical binding energy peaks at $285.08 \mathrm{eV}, 400.08 \mathrm{eV}$ and $533.08 \mathrm{eV}$, indicating that MR-CDs mainly consisted of $\mathrm{C}(64 \%), \mathrm{O}(33 \%), \mathrm{N}(3 \%)$. The C1s high-resolution spectrum (Figure S3) revealed three blinding peaks at $284.73 \mathrm{eV}, 285.78 \mathrm{eV}$ and $288.33 \mathrm{eV}$, which were attributed to $\mathrm{C}-\mathrm{C}, \mathrm{C}-\mathrm{O} / \mathrm{C}-\mathrm{N}$ and $\mathrm{C}=\mathrm{O}$ bands, respectively. The high-resolution spectrum of O1s (Figure S3) showed one peak at $532.63 \mathrm{eV}$, which was assigned to $\mathrm{C}=\mathrm{O}$ bands. Moreover, the N1s spectrum (Figure 2f) could be deconvoluted into two peaks at $399.98 \mathrm{eV}$ and $401.13 \mathrm{eV}$, which were pyrrolic-like $\mathrm{N}$ and graphitic $\mathrm{N}$, respectively [43]. The presence of pyrrolic-like $N$ could contribute to the $\pi$-conjugated system with a pair of $\pi$-electrons in MR-CDs [44]. The analyses of FTIR and XPS suggested that the surface of MR-CDs had sufficient oxygen-containing functional groups, such as- $\mathrm{OH}$ and- $\mathrm{COOH}$ groups, and these groups gave the MR-CDs excellent water solubility.

\subsection{Stability of $M R-C D s$}

Fluorescence stability of MR-CDs is important for their applications. To evaluate the photostability of MR-CDs, they were stored at room temperature in the dark, and the fluorescence intensities of MR-CDs were investigated every five days. As shown in Figure 3a, there was hardly any variation in fluorescence intensity, which enables the MR-CDs as fluorescent probe for long-term measurement. In addition, the photobleaching resistance of MR-CDs was measured through continuously irradiating with $300 \mathrm{~nm}$ ultraviolet light, and the fluorescence intensity of MR-CDs was recorded every five minutes. As shown in Figure 3b, the fluorescence intensity of MR-CDs changed slightly and kept about $80 \%$ of the initial intensity even after $100 \mathrm{~min}$ irradiation. The photobleaching resistance was higher than that of the conventional fluorophores, indicating the MR-CDs can be used as an alternative for fluorescence detection $[45,46]$.
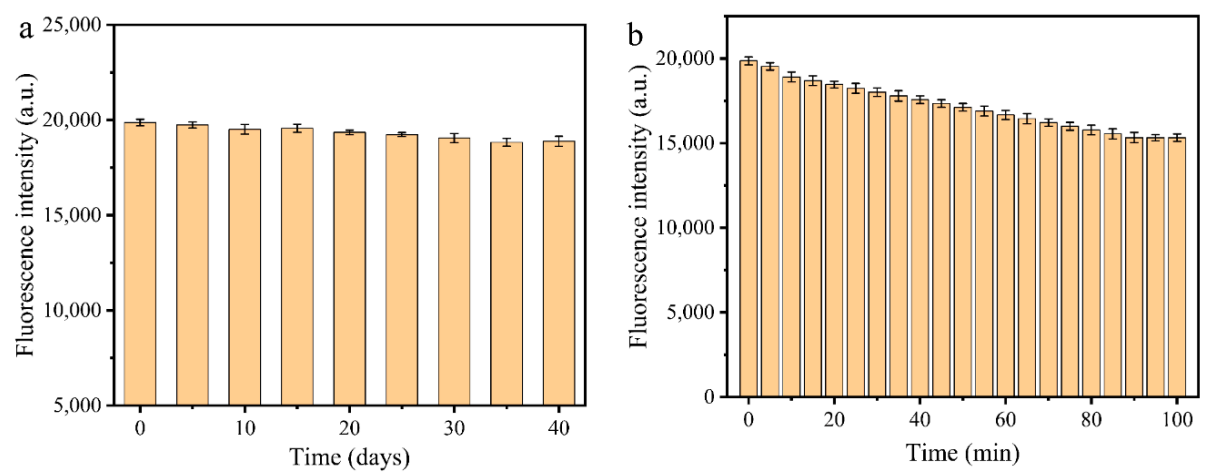

Figure 3. Fluorescence stability of MR-CDs. (a) Storage time in dark condition; (b) UV-illumination time. 


\section{4. $p H$-Dependence of $M R-C D s$}

In order to research the fluorescence responses of MR-CDs to $\mathrm{pH}$, the fluorescence $\mathrm{pH}$ titration experiment of MR-CDs was investigated. From Figure 4a, MR-CDs showed the strongest fluorescence when $\mathrm{pH}$ value ranged from 1.0 to 3.0. However, fluorescence intensity decreased dramatically when $\mathrm{pH}$ value raised from 3.0 to 13.0 (approximately 19-fold decrescent for MR-CDs). This indicated that MR-CDs were extremely sensitive to protons. Figure $4 b, c$ displays the plots of their fluorescence-quenching efficiency versus $\mathrm{pH}$ value in the range of 4.0-7.5 and 7.5-13.0 (Table 1). The fluorescence reversibility is essential for MR-CDs as a reliable $\mathrm{pH}$ probe. The $\mathrm{pH}$ response reversibility was tested when $\mathrm{pH}$ was cycled between 2.0 and 8.0. As shown in Figure 4d, MR-CDs showed excellent fluorescence reversibility and photostability, which is more favorable for real-time monitoring of $\mathrm{pH}$ fluctuation.
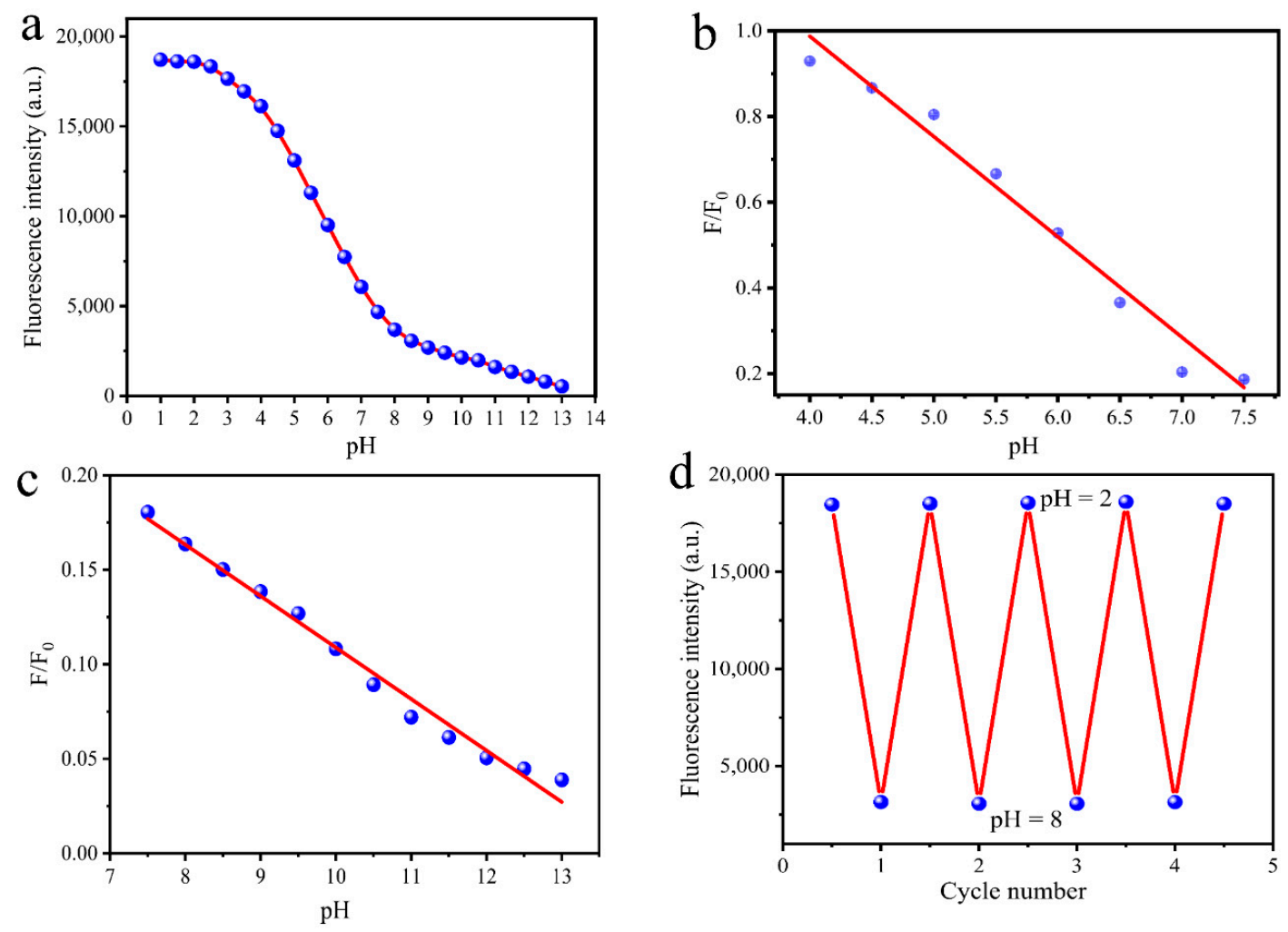

Figure 4. (a) Fluorescence intensity of MR-CDs with different $\mathrm{pH}$ values. Calibration curve of quenching efficiency $\left(F / F_{0}\right)$ and $\mathrm{pH}$ with a range from (b) 4.0-7.5 and (c) 7.5-13.0; (d) fluorescence reversibility of MR-CDs.

Table 1. Regression equation between quenching efficiency and $\mathrm{pH}$.

\begin{tabular}{ccc}
\hline $\mathbf{p H}$ Linear Range & Regression Equation & Correlation Coefficient $\left(\mathbf{R}^{\mathbf{2}}\right)$ \\
\hline $4.0-7.5$ & $F / F_{0}=-0.2342 \mathrm{pH}+1.9245$ & 0.984 \\
$7.5-13.0$ & $F / F_{0}=-0.0272 \mathrm{pH}+0.3182$ & 0.985 \\
\hline
\end{tabular}

The relationship between $\mathrm{pH}$ value and fluorescence intensity at $450 \mathrm{~nm}$ can be expressed by the Henderson-Hasselbalch-type mass action equation [47],

$$
\log \left[\frac{F_{\max }-F}{F-F_{\min }}\right]=\mathrm{pH}-\mathrm{pKa}
$$


where $F$ is the observed fluorescence intensity of MR-CDs; $F_{\max }$ and $F_{\min }$ are the fluorescence intensity of MR-CDs in its acid ( $\mathrm{pH}$ 3.5) and conjugate base ( $\mathrm{pH} 7.5)$, respectively. The $\mathrm{pKa}$ value of MR-CDs was calculated to be $5.75 \pm 0.03$ (Figure S4), which indicated that MR-CDs are suitable for studying acidic organelles.

The XPS spectra of MR-CDs showed that there were two different chemical states of nitrogen on the surface of MR-CDs, pyridinic nitrogen and graphitic nitrogen. However, only pyridine nitrogen groups $(\mathrm{C}=\mathrm{N}-\mathrm{C})$ can accept protons [48]. The variation of fluorescence versus $\mathrm{pH}$ could be ascribed to the reversible protonation and deprotonation of the pyridine nitrogen. The decrease of $\mathrm{pH}$-induced protonation of pyridine nitrogen atoms of MR-CDs. Subsequently, the protons transferred from protonated nitrogen atoms to conjugated carbon structure, which increased the fluorescence intensity of MR-CDs [49]. To reveal the pH-response mechanism of CDs, zeta potentials of CDs with different $\mathrm{pH}$ values were investigated. As shown in Figure S5, with the increase of $\mathrm{pH}$ value, zeta potentials of CDs decreased form $+5.4 \mathrm{mV}$ to $-29.9 \mathrm{mV}$. The isoelectric point of the CDs was determined to be 4.5. The zeta potentials of CDs in strong alkaline conditions showed $\mathrm{pH}$-induced deprotonation of pyridine nitrogen groups, which can oppose aggregation by electrostatic repulsion [50].

In addition, in acidic medium, the formation of hydrogen bonds of carboxyl and hydroxyl groups increased the conformational rigidity of MR-CDs and therefore promoted fluorescence emission as well [51]. The fluorescence-quenching of MR-CDs at high $\mathrm{pH}$ value, may be attributed to the deprotonation of pyridinic nitrogen atoms, which enlarged the band gap energy of MR-CDs and caused fluorescence to be weak under alkaline conditions [52].

\subsection{Selectivity of $M R-C D$ s}

To evaluate the selectivity of MR-CDs, different kinds of metal ions and anions with same concentration $(100 \mu \mathrm{M})$ were added to the MR-CDs stock solution, then the fluorescence-quenching efficiency of MR-CDs was measured. From Figure 5a,b, compared with other ions, $\mathrm{Cr}$ (VI) and Fe(III) showed significantly quenching effect on MR-CDs. Except for Fe(III) ions, other co-existence ions exhibited negligible influence on the fluorescence-quenching of $\mathrm{Cr}(\mathrm{VI})$ to MR-CDs. The interference of Fe (III) on the determination of $\mathrm{Cr}(\mathrm{VI})$ could be eliminated through adding sodium fluoride solution to the samples. As exhibited in Figure S6 with the addition of sodium fluoride, the fluorescence quenched by $\mathrm{Fe}(\mathrm{III})$ was restored, while the fluorescence quenched by $\mathrm{Cr}(\mathrm{VI})$ was not restored. Furthermore, when sodium fluoride was added to the MR-CDs solution containing Fe(III) and Cr(VI), their fluorescence intensity showed little difference from the MR-CDs solution only containing $\mathrm{Cr}(\mathrm{VI})$.
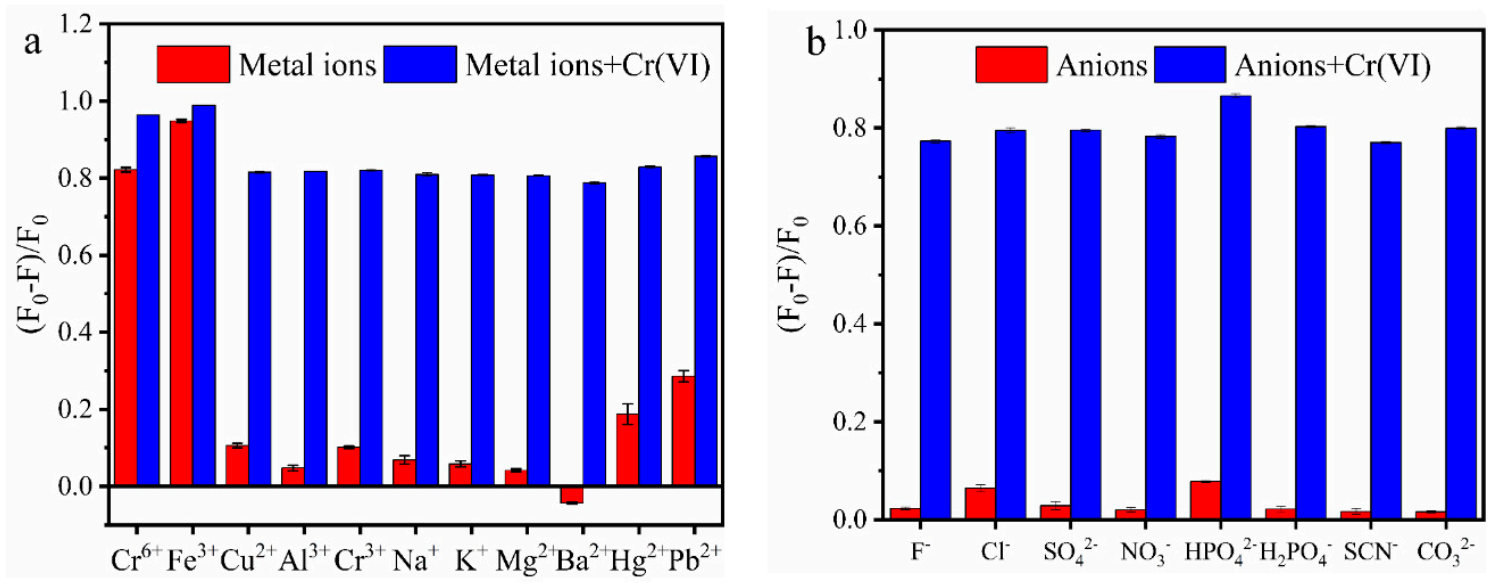

Figure 5. Fluorescence-quenching efficiency and interference effects of various metal and anion ions, where $F_{0}$ and $F$ are the fluorescence intensity of MR-CDs in the nonexistence and existence of various interfering ions under the excitation wavelength of $300 \mathrm{~nm}$. (a) Metal ions; (b) anions. 


\subsection{Detection of $\mathrm{Cr}(\mathrm{VI})$}

The MR-CDs were used to detect $\mathrm{Cr}(\mathrm{VI})$ in aqueous solution. Because MR-CDs exhibited stronger fluorescence intensity in acidic conditions, $\mathrm{Cr}(\mathrm{VI})$ ions were determined at $\mathrm{pH}$ 2.5. As shown in Figure 6a, the fluorescence intensity of MR-CDs at $450 \mathrm{~nm}$ reduced with the concentrations of $\mathrm{Cr}(\mathrm{VI})$ from 0 to $500 \mu \mathrm{M}$. The curve of fluorescence-quenching efficiency versus the concentration of $\mathrm{Cr}(\mathrm{VI})$ was plotted in Figure $6 \mathrm{~b}$. The fluorescence-quenching efficiency of MR-CDs showed a linear relationship with the concentration of $\mathrm{Cr}(\mathrm{VI})$ within the range of 0.2 to $50 \mu \mathrm{M}$. The calibration equation $F_{0} / F=0.03[\mathrm{Cr}(\mathrm{VI})]+1.02\left(R^{2}=0.988\right)$ was developed and the limit of detection (LOD) was $20 \mathrm{nM}(\mathrm{S} / \mathrm{N} \geq 3)$. As listed in Table 2, the LOD was lower than that reported previously, and also lower than the standard for drinking water quality of the WHO.
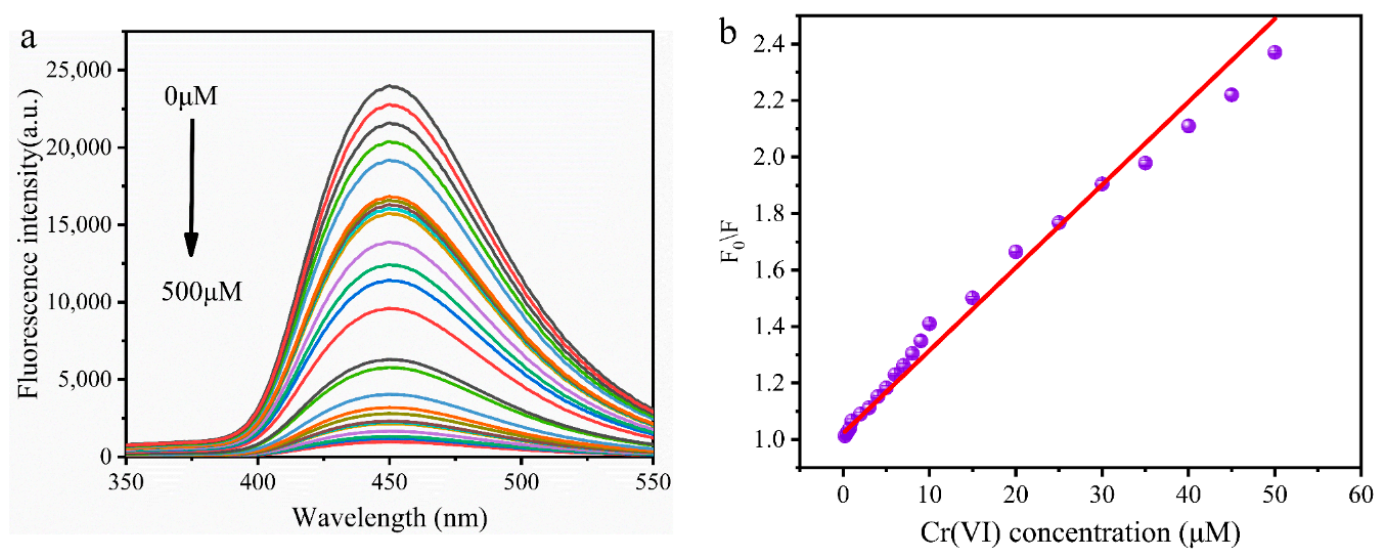

Figure 6. (a) Emission spectra of MR-CDs solution with various concentrations of $\mathrm{Cr}$ (VI) (from top to bottom: $0,0.2,0.4,0.6,0.8,1.0,2.0,4.0,6.0,8.0,10,20,30,40,50,100,200,300,400$ and $500 \mu \mathrm{M}$ ); (b) plot of the quenching efficiency against the concentration of $\mathrm{Cr}(\mathrm{VI})$.

Table 2. Comparison of different CDs for the detection of $\mathrm{Cr}(\mathrm{VI})$.

\begin{tabular}{ccccc}
\hline Methods & Materials & Linear Range $(\mu \mathbf{M})$ & LOD $(\mu \mathbf{M})$ & Citations \\
\hline N, S-CDs & Citric acid and thiourea & $1-10$ & 0.20 & {$[19]$} \\
N-CDs & Citric acid and glycine & $5-200$ & 4.16 & {$[18]$} \\
N, S-CDs & Thiourea and citric acid & $1-10$ & 0.2 & {$[19]$} \\
Green synthesis-CDs & Peanut & $2-10$ & 1.9 & {$[53]$} \\
GQDs & g-C3N4 & $0.6-300$ & 0.15 & {$[54]$} \\
MR-CDs & D-glucose and L-tryptophan & $0.2-50$ & 0.02 & This work \\
\hline
\end{tabular}

\subsection{Practical Application}

$\mathrm{Cr}(\mathrm{VI})$ in water supply systems is almost all from fixtures, faucets and pipes that contain chromium. In this study, MR-CDs were applied to detect $\mathrm{Cr}(\mathrm{VI})$ in tap water samples. After adding 1.0, 5.0 and $10.0 \mu \mathrm{M} \mathrm{Cr}(\mathrm{VI})$ into tap water, recovery assays were performed. As can be seen in Table 3, the recoveries were between $95.8 \%$ and $98.94 \%$, and relative standard deviations (RSDs) were less than $3.17 \%$. The results indicated that the MR-CDs are suitable for quantitative determination of $\mathrm{Cr}(\mathrm{VI})$ in water samples.

Table 3. Recoveries of $\mathrm{Cr}(\mathrm{VI})$ in tap water samples detected by the proposed method $(n=5)$.

\begin{tabular}{ccccc}
\hline Samples & Added (uM) & Found (uM) & Recovery (\%) & RSD (\%) \\
\hline 1 & 0 & Not detected & - & - \\
2 & 1.0 & 0.958 & 95.8 & 3.17 \\
3 & 5.0 & 4.809 & 96.18 & 2.63 \\
4 & 10.0 & 9.894 & 98.94 & 1.70 \\
\hline
\end{tabular}




\section{Conclusions}

MR-CDs were prepared through hydrothermal treatment of L-tryptophan and D-glucose at $\mathrm{pH}$ 1.0. Compared with L-tryptophan, the introduction of D-glucose significantly improved the fluorescence of MR-CDs. Furthermore, low $\mathrm{pH}$ promoted the formation of fluorescent products and inhibited their consumption by influencing certain stages of the Maillard reaction. The MR-CDs showed excellent photostability with the quantum yield of $18 \%$. Reversible protonation and deprotonation of pyridine nitrogen resulted in the fluorescence intensity of MR-CDs sensitive to $\mathrm{pH}$ variation. The fluorescence-quenching efficiency of MR-CDs showed a broad linear relationship with the $\mathrm{pH}$ value in the range of 4.0 to 7.5 and 7.5-13.0, respectively. Based on the masking of sodium fluoride on Fe(III), the MR-CDs exhibited great selectivity to $\mathrm{Cr}(\mathrm{VI})$. On this basis, MR-CDs showed a wide linear range for $\mathrm{Cr}(\mathrm{VI})$ within the concentration of $0.2-50 \mu \mathrm{M}$ and had a low detection limit of $20 \mathrm{nM}$. Furthermore, the MR-CDs were used to detect $\mathrm{Cr}(\mathrm{VI})$ in tap water samples. The recoveries were between $95.8 \%$ and $98.94 \%$, and RSDs were less than $3.17 \%$.

Supplementary Materials: The following are available online at http://www.mdpi.com/2079-4991/10/10/1924/s1, Figure S1: General scheme of the Maillard reaction adapted from Hodge. Figure S2: Three-dimensional spectrum of MR-CDs. Figure S3. (a) High-resolution spectrum of C1s; (b) high-resolution spectrum of O1s. Figure S4: Fitting curve of the Henderson-Hasselbalch equation $\left(R^{2}=0.99\right)$. Figure S5: Zeta potentials of MR-CDs in solutions of different $\mathrm{pH}$ value. Figure S6. (a) Fluorescence emission spectra of MR-CDs with $\mathrm{Fe}^{3+}, \mathrm{Cr}^{6+}$ and $\mathrm{F}^{-}$ions (the concentration of $\mathrm{Fe}^{3+}, \mathrm{Cr}^{6+}$ and $\mathrm{F}^{-}$were $100 \mu \mathrm{M}, 100 \mu \mathrm{M}$ and $1 \mathrm{mM}$, respectively); (b) fluorescence-quenching efficiency of various ions. (0: MR-CDs, 1: MR-CDs+Fe ${ }^{3+}, 2: \mathrm{MR}^{-C D s}+\mathrm{Cr}^{6+}$, 3: $\mathrm{MR}-\mathrm{CDs}+\mathrm{Fe}^{3+}+\mathrm{Cr}^{6+}, 4: \mathrm{MR}-\mathrm{CDs}+\mathrm{Fe}^{3+}+\mathrm{F}^{-}$, 5: $\left.\mathrm{MR}-\mathrm{CDs}+\mathrm{Fe}^{3+}+\mathrm{Cr}^{6+}+\mathrm{F}^{-}\right)$.

Author Contributions: Conceptualization, B.T.; methodology, Z.F.; data curation, Y.M. and Y.L.; software, M.G.; validation, X.H. and X.Z.; formal analysis, S.M. and Y.N.; writing-original draft preparation, Z.M.; writing-review and editing, Z.M., Z.F. and B.T.; supervision and funding acquisition, B.T.; All authors have read and agreed to the published version of the manuscript.

Funding: This research was funded by National Key Research and Development Program of China (2018YFC1604204), Natural Science Foundation of Heilongjiang Province (LH2019C020) and the Harbin Science and Technology Innovation Talent Fund (2017RALXJ002).

Conflicts of Interest: The authors declare no conflict of interest.

\section{References}

1. Namdari, P.; Negahdari, B.; Eatemadi, A. Synthesis, properties and biomedical applications of carbon-based quantum dots: An updated review. Biomed. Pharmacother. 2017, 87, 209-222. [CrossRef] [PubMed]

2. Zuo, P.; Lu, X.; Sun, Z.; Guo, Y.; He, H. A review on syntheses, properties, characterization and bioanalytical applications of fluorescent carbon dots. Microchim. Acta 2016, 183, 519-542. [CrossRef]

3. Ahmad, W.; Bashammakh, A.S.; Al-Sibaai, A.A.; Alwael, H.; El-Shahawi, M.S. Trace determination of Cr(III) and $\mathrm{Cr}(\mathrm{VI})$ species in water samples via dispersive liquid-liquid microextraction and microvolume UV-Vis spectrometry. Thermodynamics, speciation study. J. Mol. Liq. 2016, 224, 1242-1248. [CrossRef]

4. Tuerhong, M.; Xu, Y.; Yin, X.-B. Review on carbon dots and their applications. Chin. J. Anal. Chem. 2017, 45, 139-150. [CrossRef]

5. Shi, X.; Wei, W.; Fu, Z.; Gao, W.; Zhang, C.; Zhao, Q.; Deng, F.; Lu, X. Review on carbon dots in food safety applications. Talanta 2019, 194, 809-821. [CrossRef]

6. Maillard, C.L. Action des acides aminés sur les sucres; formation des mélanoïdines par voie methodique. Comptes R. Acad. Sci. 1912, 154, 66-68.

7. Bastos, D.; Monaro, E.R.; Siguemoto, E.; Sefora, M. Maillard Reaction Products in Processed Food: Pros and Cons. In Food Industrial Processes; InTech: London, UK, 2012; pp. 281-300.

8. Bosch, L.; Alegría, A.; Farré, R.; Clemente, G. Fluorescence and color as markers for the Maillard reaction in milk-cereal based infant foods during storage. Food Chem. 2007, 105, 1135-1143. [CrossRef]

9. Matiacevich, S.B.; Buera, M.P. A critical evaluation of fluorescence as a potential marker for the Maillard reaction. Food Chem. 2006, 95, 423-430. [CrossRef]

10. Dong, J.X.; Song, X.F.; Shi, Y.; Gao, Z.F.; Li, B.L.; Li, N.B.; Luo, H.Q. A potential fluorescent probe: Maillard reaction product from glutathione and ascorbic acid for rapid and label-free dual detection of $\mathrm{Hg} 2+$ and biothiols. Biosens. Bioelectron. 2016, 81, 473-479. [CrossRef] 
11. Wang, J.; Wang, C.F.; Chen, S. Amphiphilic egg-derived carbon dots: Rapid plasma fabrication, pyrolysis process, and multicolor printing patterns. Angew. Chem. Int. Edit. 2012, 51, 9297-9301. [CrossRef]

12. Wang, L.; Zhou, H.S. Green synthesis of luminescent nitrogen-doped carbon dots from milk and its imaging application. Anal. Chem. 2014, 86, 8902-8905. [CrossRef] [PubMed]

13. Sahu, S.; Behera, B.; Maiti, T.K.; Mohapatra, S. Simple one-step synthesis of highly luminescent carbon dots from orange juice: Application as excellent bio-imaging agents. Chem. Commun. 2012, 48, 8835-8837. [CrossRef] [PubMed]

14. Földi, C.; Dohrmann, R.; Matern, K.; Mansfeldt, T. Characterization of chromium-containing wastes and soils affected by the production of chromium tanning agents. J. Soils Sediments 2013, 13. [CrossRef]

15. GracePavithra, K.; Jaikumar, V.; Kumar, P.S.; SundarRajan, P. A review on cleaner strategies for chromium industrial wastewater: Present research and future perspective. J. Clean. Prod. 2019, 228, 580-593. [CrossRef]

16. Borthiry, G.R.; Antholine, W.E.; Kalyanaraman, B.; Myers, J.M.; Myers, C.R. Reduction of hexavalent chromium by human cytochrome b5: Generation of hydroxyl radical and superoxide. Free Radic. Biol. Med. 2007, 42, 738-755. [CrossRef] [PubMed]

17. World Health Organization. Guidelines for Drinking-Water Quality; World Health Organization: Geneva, Switzerland, 1998; Volume 2, pp. 206-215.

18. Wang, H.; Liu, S.; Xie, Y.; Bi, J.; Li, Y.; Song, Y.; Cheng, S.; Li, D.; Tan, M. Facile one-step synthesis of highly luminescent $\mathrm{N}$-doped carbon dots as an efficient fluorescent probe for chromium(vi) detection based on the inner filter effect. New J. Chem. 2018, 42, 3729-3735. [CrossRef]

19. Zhang, H.; Huang, Y.; Hu, Z.; Tong, C.; Zhang, Z.; Hu, S. Carbon dots codoped with nitrogen and sulfur are viable fluorescent probes for chromium(VI). Microchim. Acta 2017, 184, 1547-1553. [CrossRef]

20. Wencel, D.; Abel, T.; McDonagh, C. Optical chemical pH sensors. Anal. Chem. 2014, 86, 15-29. [CrossRef]

21. Shan, D.; Hsieh, J.-T.; Bai, X.; Yang, J. Citrate-based fluorescent biomaterials. Adv. Healthc. Mater. 2018, 7, 1800532. [CrossRef]

22. Ding, C.Q.; Zhu, A.W.; Tian, Y. Functional surface engineering of C-dots for fluorescent biosensing and in vivo bioimaging. Acc. Chem. Res. 2014, 47, 20-30. [CrossRef]

23. Sun, M.; Du, L.; Yu, H.; Zhang, K.; Liu, Y.; Wang, S. An intramolecular charge transfer process based fluorescent probe for monitoring subtle $\mathrm{pH}$ fluctuation in living cells. Talanta 2017, 162, 180-186. [CrossRef] [PubMed]

24. Joniak, J.; Stankovičová, H.; Filo, J.; Gaplovská-Kyselá, K.; Garaj, V.; Cigáň, M. Small-molecule coumarin fluorescent $\mathrm{pH}$ probes for extremely acidic conditions. Sens. Actuators B Chem. 2020, 307, 127646. [CrossRef]

25. Zhan, Y.H.; Liu, W.; Sun, R.; Li, X.S.; Ge, J.F. Diaminodibenzoxanthenium based near infrared pH probes with lower pK(a). Dyes Pigment. 2016, 132, 223-229. [CrossRef]

26. Gao, Q.; Du, J.; Liu, H.; Lu, S.; Zhou, X.; Yang, C. A hemicyanine-based optical probe for biomembranes and intracellular pH sensing. J. Lumin. 2018, 202, 246-252. [CrossRef]

27. English, D.S.; Pell, L.E.; Yu, Z.; Barbara, P.F.; Korgel, B.A. Size tunable visible luminescence from individual organic monolayer stabilized silicon nanocrystal quantum dots. Nano Lett. 2002, 2, 681-685. [CrossRef]

28. Matiacevich, S.B.; Santagapita, P.R.; Buera, M.P. Fluorescence from the maillard reaction and its potential applications in food science. Crit. Rev. Food Sci. Nutr. 2005, 45, 483-495. [CrossRef]

29. Berrens, L. Fluorescent intermediates in the Maillard reaction. Recl. des Trav. Chim. des Pays-Bas 1966, 85, 17-1128. [CrossRef]

30. Hodge, J.E. Dehydrated foods, chemistry of browning reactions in model systems. J. Agric. Food Chem. 1953, 1, 928-943. [CrossRef]

31. Wang, H.Y.; Qian, H.; Yao, W.R. Melanoidins produced by the Maillard reaction: Structure and biological activity. Food Chem. 2011, 128, 573-584. [CrossRef]

32. Fu, Y.; Zhang, Y.; Soladoye, O.P.; Aluko, R.E. Maillard reaction products derived from food protein-derived peptides: Insights into flavor and bioactivity. Crit. Rev. Food Sci. Nutr. 2019, 1-14. [CrossRef]

33. DeMan, J.M.; Finley, J.; Hurst, W.J.; Lee, C. Principles of Food Chemistry, 4th ed.; Springer International Publishing: Cham, Switzerlan, 2018. [CrossRef]

34. Kumar, N.; Raghavendra, M.; Tokas, J.; Singal, H.R. Chapter 10 - Flavor addition in dairy products: Health benefits and risks. In Nutrients in Dairy and Their Implications on Health and Disease; Watson, R.R., Collier, R.J., Preedy, V.R., Eds.; Academic Press: St. Salt Lake City, UT, USA, 2017; pp. 123-135.

35. Martins, S.I.F.S.; Jongen, W.M.F.; Van Boekel, M.A.J.S. A review of Maillard reaction in food and implications to kinetic modelling. Trends Food Sci. Technol. 2000, 11, 364-373. [CrossRef] 
36. Zhou, N.; Zhang, X.; Shi, Y.; Li, Z.; Feng, Z. Nitrogen-doped carbon dot mediated fluorescence on-off assay for highly sensitive detection of I- and Br- ions. New J. Chem. 2018, 42, 14332-14339. [CrossRef]

37. Feng, Z.B.; Li, Z.L.; Zhang, X.W.; Shi, Y.P.; Zhou, N. Nitrogen-doped carbon quantum dots as fluorescent probes for sensitive and selective detection of nitrite. Molecules 2017, 22, 10. [CrossRef]

38. Wang, Z.; Xu, C.; Lu, Y.; Chen, X.; Yuan, H.; Wei, G.; Ye, G.; Chen, J. Fluorescence sensor array based on amino acid derived carbon dots for pattern-based detection of toxic metal ions. Sens. Actuators B Chem. 2017, 241, 1324-1330. [CrossRef]

39. Pei, S.; Zhang, J.; Gao, M.; Wu, D.; Yang, Y.; Liu, R. A facile hydrothermal approach towards photoluminescent carbon dots from amino acids. J. Colloid Interface Sci. 2015, 439, 129-133. [CrossRef] [PubMed]

40. Yoshinaga, T.; Akiu, M.; Iso, Y.; Isobe, T. Photoluminescence properties of 1-cysteine-derived carbon dots prepared in non-aqueous and aqueous solvents. J. Lumin. 2020, 224, 117260. [CrossRef]

41. Feng, Z.; Li, Z.; Zhang, X.; Xu, G.; Zhou, N. Fluorescent carbon dots with two absorption bands: Luminescence mechanism and ion detection. J. Mater. Sci. 2018, 53, 6459-6470. [CrossRef]

42. Huang, S.; Wang, L.; Huang, C.; Xie, J.; Su, W.; Sheng, J.; Xiao, Q. A carbon dots based fluorescent probe for selective and sensitive detection of hemoglobin. Sens. Actuators B Chem. 2015, 221, 1215-1222. [CrossRef]

43. Sheng, Z.-H.; Shao, L.; Chen, J.-J.; Bao, W.-J.; Wang, F.-B.; Xia, X.-H. Catalyst-free synthesis of nitrogen-doped graphene via thermal annealing graphite oxide with melamine and its excellent electrocatalysis. ACS Nano 2011, 5, 4350-4358. [CrossRef]

44. Dai, S.; Liu, Z.; Zhao, B.; Zeng, J.; Hu, H.; Zhang, Q.; Chen, D.; Qu, C.; Dang, D.; Liu, M. A high-performance supercapacitor electrode based on N-doped porous graphene. J. Power Sources 2018, 387, 43-48. [CrossRef]

45. Xiong, Y.; Schneider, J.; Ushakova, E.V.; Rogach, A.L. Influence of molecular fluorophores on the research field of chemically synthesized carbon dots. Nano Today 2018, 23, 124-139. [CrossRef]

46. Xiong, Y.; Schneider, J.; Reckmeier, C.J.; Huang, H.; Kasák, P.; Rogach, A.L. Carbonization conditions influence the emission characteristics and the stability against photobleaching of nitrogen doped carbon dots. Nanoscale 2017, 9, 11730-11738. [CrossRef] [PubMed]

47. Li, Z.; Yu, C.; Chen, Y.; Zhuang, Z.; Tian, B.; Liu, C.; Jia, P.; Zhu, H.; Sheng, W.; Zhu, B. A novel water-soluble fluorescent probe with ultra-sensitivity over a wider $\mathrm{pH}$ range and its application for differentiating cancer cells from normal cells. Analyst 2019, 144, 6975-6980. [CrossRef] [PubMed]

48. Qian, Z.; Ma, J.; Shan, X.; Feng, H.; Shao, L.; Chen, J. Highly luminescent N-doped carbon quantum dots as an effective multifunctional fluorescence sensing platform. Chem. (Weinh. der Bergstr. Ger.) 2014, 20. [CrossRef]

49. Wang, W.-J.; Xia, J.-M.; Feng, J.; He, M.-Q.; Chen, M.-L.; Wang, J.-H. Green preparation of carbon dots for intracellular pH sensing and multicolor live cell imaging. J. Mater. Chem. B 2016, 4, 7130-7137. [CrossRef] [PubMed]

50. Zhang, Y.; Liang, S.; Zhang, J.; Chi, Y.; Tian, B.; Li, L.; Jiang, B.; Li, D.; Feng, Z.; Liu, C. Preparation of whey protein isolate nanofibrils by microwave heating and its application as carriers of lipophilic bioactive substances. LWT 2020, 125, 109213. [CrossRef]

51. Li, C.; Zhang, X.; Zhang, W.; Qin, X.; Zhu, C. Carbon quantum dots derived from pure solvent tetrahydrofuran as a fluorescent probe to detect $\mathrm{pH}$ and silver ion. J. Photochem. Photobiol. A Chem. 2019, 382, 111981. [CrossRef]

52. Liu, X.; Yang, C.; Zheng, B.; Dai, J.; Yan, L.; Zhuang, Z.; Du, J.; Guo, Y.; Xiao, D. Green anhydrous synthesis of hydrophilic carbon dots on large-scale and their application for broad fluorescent $\mathrm{pH}$ sensing. Sens. Actuators B Chem. 2018, 255, 572-579. [CrossRef]

53. Roshni, V.; Misra, S.; Santra, M.K.; Ottoor, D. One pot green synthesis of C-dots from groundnuts and its application as $\mathrm{Cr}(\mathrm{VI})$ sensor and in vitro bioimaging agent. J. Photochem. Photobiol. A Chem. 2019, 373, 28-36. [CrossRef]

54. Rong, M.; Lin, L.; Song, X.; Wang, Y.; Zhong, Y.; Yan, J.; Feng, Y.; Zeng, X.; Chen, X. Fluorescence sensing of chromium (VI) and ascorbic acid using graphitic carbon nitride nanosheets as a fluorescent "switch". Biosens. Bioelectron. 2015, 68, 210-217. [CrossRef]

(C) 2020 by the authors. Licensee MDPI, Basel, Switzerland. This article is an open access article distributed under the terms and conditions of the Creative Commons Attribution (CC BY) license (http://creativecommons.org/licenses/by/4.0/). 